thing as entering it, thereby showing that the ether produced no effect upon the uterus in diminishing its contractile powers. At half-past four, forty drops of sedative solution of opium were given her; in less than two minutes, she was fast asleep and snoring, which we attributed to the ether, and not to the opium. Examination was again made at a quarter to five, five, six, and seven o'clock; the uterus still continuing as firm as before, it was agreed that rest should be given her for a few hours. The pulse was now 120 . At ten we met, and found the rigidity of the uterus had in some measure given way; so that, by steady perseverance, the second foot was brought down, and the delivery completed at a quarter to eleven. I wished, at this latter time, to have used the ether again, to have prevented her from suffering during the turning; but the gentleman whose case it was feared some danger might ensue, as he had been called in to see her about three years before for some affection of the heart. During the second exhibition of the ether, she was not conscious of anything; she had previously been and was then grasping her friend's hand with great force during the attempt to bring down the foot; but as the ether took effect, she gradually withdrew her fingers, and laid back her head in a perfectly quiescent state.

April 15th, I visited her, and found her quite as well as she would liave been at the same period after a natural labour. To-day, the gentleman attending her told me she had not had a bad symptom: her own expression was, that sle was better now than upon former occasions, and that, should she ever be so circumstanced again, she should beg to have the ether given to her.

The apparatus used was a bladder withont any valve, the patient consequently respiring into the bladder, and again inhaling the same. I have now performed thirty-eight different operations with the bladder, and have twice used Robinson's ap paratus. Not in one instance have $I$ seen anything approaching to asphyxia; neither has there been any cerebral congestion.

From what $I$ saw in the above case, I shall not hesitate to give the ether in any natural labour during the latter pains, when the head is commencing to bear upon the perinæum, that being the point at which I consider the ether to be of benefit: to give it at an early stage would be perfectly useless, as it would not act upon the uterus; and it is only when the head is approaching the outlet that there is any occasion for relaxing the muscles for the egress of the child. Certainly, if used in the early part of the labour, the pains would not be felt; but as its duration is always uncertain, it would be imprudent to be following up the ether for several hours, should it be so long required.

It is probable I might not have troubled you with this, but as I am written to by practitioners in the country for my opinion with regard to the ether, I think a few accounts of its practical use and consequent effects far more beneficial for them than all the theoretical surmises which may be put forth upon the subject.-Believe me, Sir, yours obliged,

Bristol, April, 1847. J. G. LANSDOWA

\section{ON THE DISCOVERY OF THE USE OF NARCOTIC VAPOURS IN MITIGATING PAIN.} To the Elitor of THE LANCET.

SIR,- When a new discovery of wide importance is brought before the public, the individual by whose agency it is more immediately introduced is seldom suffered long to enjoy, undisturbed, the applause which is the meed of the discoverer.

"Coming events cast their shadows before."

The establishment of every great discovery has been preceded by the accumulation of isolated facts and glimmerings of the truth brought together by various labourers. When the fulness of time is come, these facts and gliminerings supply the materials out of which the truth itself is deduced, and a discovery results. The early pioneers of a discovery often deserve a larger portion of honour than those who bring it tangibly before the world. These remarks particularly apply to the new method of rendering patients insensible to pain by the inhalation of vapours.

The discovery of this method has been boldly claimed by Drs. Jackson and Morton: and to them must certainly be accorded the chief merit of bringing it into use. No sooner was the discovery announced, than Dr. Collyer claimed priority of invention, without, however, adducing those proofs which could alone substantiate his pretensions. Still another aspirant, Mr. Horace Wells, appears in the field, with apparently better-founded claims. History will, in due course, assign to each his just award. In the meantime, while leaving the living competitors to assert their own rights, I venture to put in a claim on behalf of the "illustrious dead."
When the new method was first noised abroad, I recollected that an institution called the Medical Pneumatic Hospital had been founded by Dr. Beddoes at Clifton; and that, in the year 1798, Humphry Davy had been called from his seclusion in Cornwall to take charge of this establishment. In it, the great chemist laid the foundation of his future fame, by making au extensive series of observations and experiments to determine the value of gases in the treatment of disease. An indistinct presentiment assured me that the powerful minds of Beddoes and Davy could not, in the course of their comprehensive researches, have overlooked the special application of the inhalation of gases to the mitigation of pain. On reperusing the beautiful work of Sir Humphry Davy, entitled " Researches chicfly concerning Nitrous Oxide and its Respiration," 8vo, 1800, I found my expectations realized. And I would earnestly recommend those who are engaged in the interesting inquiry as to the effects of the inhalation of vapours, carefully to study this work, which may be said to form a model for all future observations, and patiently to follow in the footsteps of the great father of pneumatic chemistry as applied to medicine.

I will now submit two extracts from $\mathrm{Sir} H$. Dary's writings, which will satisfactorily prove that he at least anticipated this important discovery. These extracts will probably be acceptable to those who have not an opportunity of consulting his works. It would be superfiuous to quote the many observations he made as to the effects of nitrous oxide upon man. Similar experiments have since become familiar to every one. For these and many other interesting points relating to the subject - his comprehensive mind left nothing untouched-reference must be made to his work.

"In one instance, when I had headach from indigestion, it was inmediately removed by the effects of a large dose of gas, though it afterwards returned, but with much less violence. In a second instance, a slighter degree of headach was wholly removed by two doses of gas.

"The power of the immediate operation of the gas, in removing intense physical pain, I had a very good opportunity of ascertaining.

"In cutting one of the unlucky teeth, called dentes sapientix, I experienced an extensive inflammation of the gum, accompanied with great pain, which equally destroyed the power of repose and of consistent action.

"On the day when the inflammation was most troublesome, I breathed three large doses of nitrous oxide. The pain always diminished after the first four or five inspirations; the thrilling came on as usual, and uneasiness was for a few minutes swallowed up in pleasure."*

"As nitrous oxide, in its extensive operation, appears capable of destroying physical pain, it may probably be used with advantage during surgical operations, in which no great effusion of blood takes place." $\uparrow$

The foregoing extracts I leave to speak for themselves. I feel, that by recalling attention to the admirable work from which they are taken, and which has been unaccountably overlooked, I have discharged a duty to departed worth.

I deem it right, however, before concluding, now that experiments upon the human frame are being so enthusiastically made, to adduce the caution recommended by Dr. Beddoes and Davy, against employing the nitrous oxide in the cases of hysterical females. They cite cases showing the danger of the practice.

The most appropriate termination to this letter will be found in the concluding words of the great discoverer, whose claims I have asserted:-

"An immense mass of pneumatological, chemical, and medical information must be collected, before we shall be able to operate with certainty on the human constitution.

"Pneumatic chemistry, in its application to medicine, is an art in infancy, weak, almost useless, but apparently possessed of capabilities of improvement. To be rendered strong and mature, she must be nourished by facts, strengthened by exercise, and cautiously directed in the application of her powers, by external scepticism."

Fotting-hill, March, 1847.

Robert Barnes, M.B. Lond.

\section{THE POISONED MIND.}

To the Editor of The Larcet.

Srr, - The mind may be poisoned as well as the body. I am consulted by young men who, after sexual intemperance, perhaps after an attack of gonorrlow, have been to consult some of the advertising quacks of the day. By these persons, * Sir Humphry's Collected Works. By John Davy, M.D., 1839, p, 270,
tol. ii. 